\title{
Are there differences between officers and ratings on merchant vessels concerning effort-reward imbalance: a cross-sectional maritime field study
}

\author{
Marcus Oldenburg ${ }^{1}\left[\right.$ D Hans-Joachim Jensen ${ }^{1,2}$
}

Received: 22 September 2020 / Accepted: 30 March 2021 / Published online: 29 October 2021

(c) The Author(s) 2021

\begin{abstract}
Purpose Today, measures to economise in the operation of ships can cause either an effort-reward imbalance or health impairments. The goal of this study was to assess the risk of effort-reward imbalance including overcommitment among officers and ratings on merchant vessels during their assignments and to evaluate lifestyle factors of seafarers as well as the health-promoting conditions on board.

Methods A study sample of 308 male seafarers was examined during a total of 20 sea voyages on German container ships (participation rate $91.9 \%$ ).

Results Only 11 seafarers were identified as having an increased health risk of an effort-reward imbalance (ER ratio $>1)$. Officers tended to have a higher risk of an elevated ratio than ratings $(4.4 \%$ vs. $3.1 \%)$ and also showed a significantly higher risk of an ER ratio above the median $(58.8 \%$ vs. $41.8 \% ; p=0.022)$. Compared to land-based populations, the average overcommitment score of seafarers was high (17.9)—particularly among officers $(20.3$ vs. $16.5 ; p=0.031)$. This corresponded to an elevated risk of overcommitment among officers compared to ratings (OR 2.14; 95\% CI 1.78-2.37). This elevated risk remained significant after adjustment for age (OR 2.11; 95\% CI 1.76-2.35) and job-related stressors.

Conclusion Although an elevated risk of effort-reward imbalance was only observed in few seafarers, this study revealed a high prevalence of overcommitment particularly among officers. In the course of time, overcommitment can lead to mental exhaustion. Therefore, shipboard health-promoting conditions need to be optimised.
\end{abstract}

Keywords Maritime $\cdot$ Vessels $\cdot$ Seafarer $\cdot$ Overcommitment $\cdot$ Effort-reward imbalance

$\begin{array}{ll}\text { Abbreviations } \\ \text { CI } & \text { Confidence interval } \\ \text { ER } & \text { Effort-reward } \\ \text { ERI } & \text { Effort-reward imbalance } \\ \text { OR } & \text { Odds ratio } \\ \text { SD } & \text { Standard deviation }\end{array}$

Marcus Oldenburg

marcus.oldenburg@justiz.hamburg.de

1 Institute for Occupational and Maritime Medicine Hamburg (ZfAM), University Medical Center Hamburg-Eppendorf (UKE), Seewartenstrasse 10, 20459 Hamburg, Germany

2 Flensburg University of Applied Sciences, Flensburg, Germany

\section{Introduction}

It is well-known that maritime occupations include a high level of psychophysical strain (Carotenuto et al. 2012; Jespen et al. 2015). This can lead to psychosomatic diseases including burnout syndrome or fatigue (Oldenburg et al. 2013a; Sargent et al. 2017). It cannot be ruled out that work-related stress increases the risk of coronary diseases amongst seafarers. The higher than average age of seafarers, smoking and nutrition habits, their lack of exercise and a high stress burden on board lead to a wide variety of cardiovascular risk factors (Oldenburg et al. 2013b; Baygi et al. 2017). Some of these factors are a result of the combination of working and living on board (Hansen et al. 2005; Apostolatos et al. 2017); for example, the quite often unbalanced and high-fat diet provided, together with a reduction of leisure opportunities and thus too little exercise (Oldenburg et al. 2009; Zyriax et al. 2018). Taking this into account, specificities of food catering on board, leisure opportunities and health 
education seem to be of great relevance for occupational maritime medicine (Westenhoefer et al. 2018).

A "healthy worker effect" can be postulated for seafarers as they have to undergo medical fitness tests for nautical service every 2 years. Despite this effect, a study by Oldenburg et al. (2008) revealed signs of an increased cardiovascular risk amongst seafarers in comparison to a reference population ashore. Cardiovascular diseases were also identified as one of the most frequent causes of death among seafarers (Jaremin et al. 2003; Ehara et al. 2006).

Today, shipping crews are multinational and heterogeneous (Hansen et al. 2008). They experienced different socialisation patterns in their home countries and the occupational groups vary widely due to their diverse psychophysical challenges. Thus, it is likely that the health status and also the cardiovascular risks differ in respect of the shipboard occupational groups. Furthermore, current seafaring is characterised by increasing economisation in the operation of ships that lead to a growing workload for the crew and can cause either an effort reward imbalance or health impairment. In this context, the question arises about lifestyle factors of the crew (especially concerning sport and nutrition) and the health management on board.

Over the past 10 years, the pooling of multiple data sets into 'mega-studies' has accelerated progress in research on stress as a risk and prognostic factor for cardiovascular disease (Kivimäki and Steptoe 2018). In respect of the elevated cardiovascular disease (CVD) risk of seafarers, the Effort-Reward Imbalance (ERI) model was chosen for the present study as its explanatory power concerning work stress parameters, particularly in the case of CVD, has repeatedly been proven (Dragano et al. 2017; Gilbert-Ouimet et al. 2014). The reason for selecting the ERI model without incorporating complementary models (e.g., demand-control, organizational injustice) is that this model is the only one that is not restricted to exclusively extrinsic factors, but also includes an intrinsic component of individual coping (overcommitment). This seems to be particularly relevant in the context of this study. Furthermore, studies published so far focusing on psychological health issues of seafarers on board have never taken the crews' effort-reward imbalance into account. Besides that, it is common practice to conduct studies dealing with health strains among seafarers ashore (Sargent et al. 2017; Hjarnoe and Leppin 2014). It must be assumed that this setting is not a suitable one to reflect the psychophysical challenges on board a ship in a realistic manner. Therefore, it is desirable to analyse seafarers' psychophysical stress and health risks during their assignments on board, which generally last for many months.

The goal of this study was to assess the risk of effort-reward imbalance including overcommitment of the officers and ratings in their workplace setting. In addition, lifestyle factors of the seafarers as well as health-promoting conditions on board were evaluated to estimate the need for improved health management on board.

\section{Methods}

\section{Study sample}

All 108 German shipping companies that manage or own at least one container vessel were contacted and asked to participate in this study. It is known that the workload aboard depends on the vessel's shipping route (Baumler et al. 2020; Lochner and Duenser 2018). Particularly container ships with a shipping route in the North or Baltic Sea are subject to high proportions of port handling and only short sea passages, which the seafarers can often use to relax and recover from port-related stress. Thus, only those container vessels with the mentioned shipping routes were included in this study. Due to time restrictions or missing availability of suitable accommodation for the examiners on board, only 12 shipping companies (11.1\%) were included in this study (six with at least a second ship) (Fig. 1). Out of these shipping companies, the crews of 20 different container vessels were examined. All shipboard crew members were included in this study, regardless of their occupational group or their origin. The composition of the crews is prescribed by law (Schiffsbesetzungsverordnung (SchBesV) 2013, Federal Ministry of Transport, Building and Urban Development) and thus did not differ significantly between the various ships. Regarding socio-demographic parameters, all officers have a 3-year education at a maritime university and are responsible for management on board-in contrast to the ratings who attend basic courses at maritime schools over a period of 3 years to become able bodied seamen or ship's mechanics.

In respect of their current flag ( 6 times German, 3 times English, 5 times Antiguan-Barbudan, 4 times Cyprian and twice Liberian) (Fig. 1), the average construction years of the ships (2006), the predominance of a 3-watch system and the average number of crew members on board (16 persons; range from 11 to 24 persons), there were no differences to the characteristics of the German fleet.

A medically trained scientist accompanied the sea voyages on these 20 container ships and interviewed the whole crew on board. A total of 308 of 335 (participation rate 91.9\%) exclusively male seafarers took part in this investigation. The study sample was divided into 194 ratings (63.0\%) and 114 officers (37.0\%). 79.4\% of the ratings and only 7.4\% of the officers originated from South Asia, whereas $92.6 \%$ of the latter rank came from Europe. An additional differentiation by age resulted in a median of 37 years (range from 18 to 71 years). 
Fig. 1 Flow chart of the excluded and included German companies (status 2015). *This is the entirety of all German companies that manage or own at least one container vessel

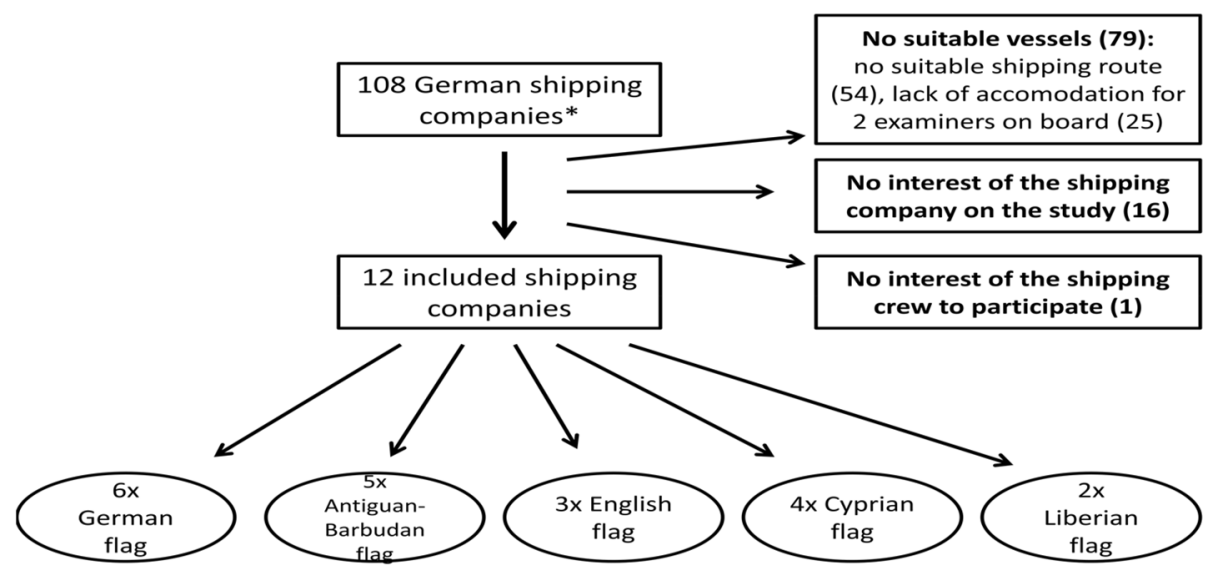

* this is the entirety of all German companies that manage or own at least one container vessel
Participation in the study was voluntary and the data collection was pseudonymised. All participants gave their written informed consent before taking part in this study. The study was approved by the Ethics Committee of the Hamburg Medical Association (no PV4395).

\section{Scope of investigation}

Objective values of work-related health information were: measurements of the seafarers' blood pressure and heart rate-as important heart parameters in field studies—carried out before and after two randomly picked shifts on board. A medical doctor measured the blood pressure on both upper arms of the seafarers participating using a manual, single-hand blood pressure monitor with a stable precision manometer (Boso Clinicus II, Jungingen, Germany). During the measurement, the seafarers were in a sitting position and had had a resting phase of at least 10 min before measuring. In cases of significantly differing blood pressure values between the left and the right upper arm or in the pre- and post-shift examination, the measurement was repeated at another time and finally the median calculated. According to the WHO definition, blood pressure is considered to be raised when systolic blood pressure is equal to or above $140 \mathrm{mmHg}$ and/or a diastolic blood pressure equal to or above $90 \mathrm{mmHg}$ (WHO 2020).

Furthermore, the interviewer with seafaring experience conducted a standardised interview on board during the crews' leisure time at high seas. Due to nowadays commonly multinational shipboard crews, the board language is in general English. Thus, the interview was also performed in English. To avoid possible comprehension problems, the psychologically trained interviewer on board provided direct support on the seafarers' questions. In addition, the interview took place in a confidential setting in the examiner's single cabin. As a quality criterion, questioning by an interviewer generally enables an immediate completeness check and the elimination of ambiguities (Edwards and Holland 2013; Jamshed 2014). The interview consisted of 2 parts (one standardised questionnaire and questions about healthpromoting conditions on board).

\section{Effort-reward imbalance questionnaire (ERI)}

To understand the health risks associated with psychomental and socioemotional work strain, an "Effort-Reward Imbalance" model was developed by Siegrist et al. (1997). This risk score correlates with the cardiovascular risk. According to this model, effort-reward imbalance results from an imbalance between professional effort (exhaustion) and reward received within the work setting (gratification). A ratio $>1$ of professional effort divided by reward received indicates a long-lasting stress experience. It should be mentioned that the cut-point 1.0 of the ER ratio has been criticised for methodological reasons, and a standard procedure is also to analyse either continuous data or to define the median or the upper tertile of the distribution as cut-point.

In the present manuscript, the long version of the ERI questionnaire (ERI-L 16 Items. Version 22.11.2012) with a four point Likert answer format is used: (1) strongly disagree, (2) disagree, (3) agree, and (4) strongly agree (Siegrist et al. 2004, 2008). Effort was measured by six items so that the total score measuring extrinsic effort varies between 6 and 24. In analogy to the effort scale, reward was determined by ten four point Likert scaled items resulting in a sum score between 10 and 40. Concerning the seafarers' effort, additional analyses were performed using the scores of the three sub-scales (esteem, promotion, and security) that provide further meaningful information in theoretical and practical terms (Siegrist et al. 2018; De Jonge and Schaufeli 2002).

In addition, characteristics such as an excessive tendency to push their limits on the job ("overcommitment") were included in the gratification model. The degree of agreement with the 6 items of the overcommitment scale 
is determined on the above-mentioned four-point Likert scale. A total sum score is formed from the answers, ranging from 6 to 24 points (Siegrist 2002). A recent study about occupational drivers revealed that high overcommitment scores (cutoff level of 15) were associated with an elevated risk for cardio-vascular diseases (Wei-Te et al. 2019). According to Lehr et al. (2010), a total value of $>16$ was regarded as a critical score. Thus, in this study the cutoff level was set at a score value of 16 .

The authors of the ERI have repeatedly evaluated the psychometric properties of the Effort-Reward Imbalance questionnaire. The data published document satisfactory internal consistency in terms of Cronbach's $\alpha$ (usually $>0.70$ ) of the three scales of effort, reward and overcommitment (Siegrist and Montano 2014). In addition, a recent study by Junior et al. (2017) examined the validation of the Effort-Reward Imbalance questionnaire and found a high Cronbach's alpha for "effort" with 0.78 , for "reward" with 0.80 and for "overcommitment" with 0.89 . These data were confirmed by other studies (Li et al. 2017). Concerning discriminant validity, significant differences were found in mean scores of effort, reward and overcommitment according to gender, age, socio-economic status, and other sociodemographic characteristics (Wahrendorf et al. 2014).

In respect of the criterion validity, several studies reported convincing sensitivity of the scales to indicate real changes over time (Siegrist et al. 2009). A high score on the ERI scales was associated with elevated risks of poor self-rated health (Siegrist et al. 2009). In total, several studies evaluated the ERI questionnaire as a valid instrument to assess adverse psychosocial work characteristics.

After the effort-reward ratio of the seafarers had been determined, the study population was divided into the groups below and above the median (Siegrist et al. 2003, 2004).

\section{Questions about health-promoting conditions on board}

After answering the Effort-Reward Imbalance questionnaire the interviewer applied an established maritime shipspecific questionnaire (Oldenburg et al. 2009). In this questionnaire, seafarers were asked about socio-demographic parameters (e.g., age, marital status, existence of children) and job-related aspects (experience at sea (years), average stay on board, average lengths of working time and daily sleep duration). Furthermore, this questionnaire dealt with health-promoting conditions on board-particularly concerning nutrition and exercise during stays on the vessel. As part of this questionnaire, the seafarers had the option to give some information in free text about the established health management on board.

\section{Statistical analysis}

Data analysis was performed with SPSS for Windows (version 20.0, SPSS GmbH Software, Munich, Germany). Continuous variables were presented as mean ( \pm standard deviation (SD)). The Pearson Chi-square test was applied to compare frequencies between groups. After testing for normal distribution, the $t$ test was used for the evaluation of differences between groups. The odds ratio (OR) including 95\% confidence intervals was calculated with binary logistic regression. The crude OR was first determined and then adjusted for age. Finally, an adjustment of the odds ratio was carried out for the average length of the working day and the daily sleep duration. All indicated $p$ values were two-sided, and a $p$ value of $<0.05$ was deemed statistically significant.

\section{Results}

Regarding socio-demographic parameters, no differences were observed between officers and ratings in age (38.5 vs. 36.6 years; n.s.), in marital status ( $71 \%$ vs. $74 \%$; n.s.) and the existence of children (68\% vs. $70 \%$; n.s.). The officers in the present study had longer seafaring experience (15.8 vs. 11.3 years; $p=0.002)$, a longer working day ( 10.4 vs. $9.3 \mathrm{~h}$; $p<0.001)$ and a shorter daily sleep duration $(7.0$ vs. $7.6 \mathrm{~h}$; $p=0.016)$. In addition, the average time spent on board varied widely between officers and ratings ( 4.8 vs. 9.2 months; $p<0.001)$.

\section{Cardiovascular parameters}

While the mean Body Mass Index was $26.4( \pm 4.1)$, slight overweight was observed in the study population (Table 1). No differences in systolic and diastolic blood pressure were measured in the occupational groups on the ship. 18 seafarers (5.8\%) showed signs of hypertension ( $R R \geq 140 / 90 \mathrm{mmHg}$ ). The resting heart rate did not differ significantly between the two occupational groups. A cross-shift comparison did not reveal any significant changes in the cardiovascular parameters (data not shown).

Even though the occupational groups did not differ in their smoking status (never vs. former/current smoker), the ratings had significantly less pack years (Table 1). There were no differences in alcohol consumption (yes/no) between the professional ranks $(p=0.396)$.

\section{Effort-reward imbalance questionnaire}

The effort score was distinctly lower than its median within the total study sample. Taking the ERI correction factor into account, the officers displayed a significantly higher effort score than the ratings. The reward score was 
Table 1 Health parameters and smoking habits of the study sample

\begin{tabular}{llll}
\hline & & \multicolumn{2}{l}{ Ranks } \\
\cline { 3 - 4 } & & Ratings (194) & Officers (114) \\
\hline Age, mean (SD) & $38.1(11.1)$ & $37.6(11.3)$ & $39.5(10.8)$ \\
Body-Mass-Index, mean (SD) & $26.4(4.1)$ & $26.3(4.2)$ & $25.8(3.7)$ \\
Blood pressure, mean (SD) & $123(10.9) / 80(10.1)$ & $122(11.4) / 79(10.2)$ & $123(10.1) / 79(9.2)$ \\
Heart rate, $b p m$ & $81.6(6.7)$ & $80.8(6.7)$ & $80.7(7.2)$ \\
Smoking rate, $n(\%)$ & & & \\
$\quad$ Never smokers & $158(51.3 \%)$ & $102(52.6 \%)$ & $56(49.1 \%)$ \\
Former smokers or current smokers & $150(48.7 \%)$ & $92(47.4 \%)$ & $58(50.9 \%)$ \\
Pack years, median (min-max) & $8.4(0.1-88)$ & $4.5(0.1-88)$ & $10.5(0.2-62)$ \\
\hline
\end{tabular}

extremely high in this study, particularly among officers. The latter finding was mainly caused by the officers' assessment of their job security $(p=0.001)$ and their job promotion. Officers and ratings demonstrated an average effort-reward (ER) ratio of 0.58 and 0.51 , respectively. A raised ratio $(>1)$ corresponding to a higher risk of an effort-reward imbalance was only found in eleven seafarers (4.4\% of officers and $3.1 \%$ of ratings). The individuals were attributed to below and above the median according to their ER ratio. Officers showed a higher crude risk of an ER ratio above the median than ratings (OR 1.62; 95\% CI 1.21-2.78) (Table 2). After adjusting for age, this elevated risk remained significant (OR 1.57; 95\% CI 1.18-2.14). Adjustment for the average length of the working day and the daily sleep duration resulted in a decreased but still significant risk of effort-reward imbalance (OR 1.32; 95\% CI 1.05-1.89).

In respect of the overcommitment scale, the seafarers' average score was 17.9. The score was higher among officers than ratings ( 20.3 vs. $16.5 ; p=0.031)$. In the comparison of the two occupational groups, officers more frequently had a tendency to push their limits on the job (74 officers $(64.9 \%)$ and 107 ratings $(55.1 \%) ; p=0.029)$. This corresponded to a more than twice as high risk of overcommitment among officers compared to ratings (crude OR 2.14; 95\% CI 1.78-2.37). This elevated risk remained significant after adjustment for age (OR 2.11; 95\% CI 1.76-2.35). When adjusting for the average length of the working day and the daily sleep duration, a lower risk was observed (OR 1.84; 95\% CI 1.74-2.07). Thus, the risk of suffering from both
Table 2 Effort-Reward Imbalance questionnaire in respect of the ranks

\begin{tabular}{|c|c|c|c|c|}
\hline & \multirow[t]{2}{*}{ Study sample (308) } & \multicolumn{3}{|l|}{ Ranks } \\
\hline & & Ratings (194) & Officers (114) & $\mathrm{p}$ \\
\hline \multicolumn{5}{|l|}{ Effort-Reward Scores, mean (SD) } \\
\hline Effort score (range 6-24) & $11.3(2.3)$ & $10.5(1.1)$ & $12.9(1.8)$ & $0.015^{\# \$}$ \\
\hline Reward score (range 10-40) & $35.5(3.1)$ & $34.5(2.8)$ & $36.9(3.2)$ & n.s. ${ }^{\#}$ \\
\hline Job security (range $2-8$ ) & $5.2(1.1)$ & $4.7(0.7)$ & $6.0(0.8)$ & $0.001^{\#}$ \\
\hline Esteem (range 4-16) & $15.5(1.3)$ & $15.2(1.4)$ & $15.7(1.6)$ & n.s. ${ }^{\#}$ \\
\hline Job promotion (range 4-16) & $14.8(1.1)$ & $14.6(1.2)$ & $15.2(1,6)$ & n.s. ${ }^{\#}$ \\
\hline \multicolumn{5}{|l|}{ Effort-Reward Imbalance } \\
\hline Ratio, mean (SD) & $0.53(0.26)$ & $0.51(0.29)$ & $0.58(0.18)$ & $0.062^{*}$ \\
\hline Increased $^{1}, n(\%)$ & $11(3.6 \%)$ & $6(3.1 \%)$ & $5(4.4 \%)$ & n.s. \\
\hline Median & & & & $0.022^{\#}$ \\
\hline$<$ Median & $160(51.9 \%)$ & $113(58.2 \%)$ & $47(41.2 \%)$ & \\
\hline$\geq$ Median & $148(48.1 \%)$ & $81(41.8 \%)$ & $67(58.8 \%)$ & \\
\hline \multicolumn{5}{|l|}{ Overcommitment } \\
\hline Score, mean (SD) & $17.9(3.1)$ & $16.5(2.9)$ & $20.3(3.4)$ & $0.031^{*}$ \\
\hline Increased $^{2}, n(\%)$ & $181(58.8 \%)$ & $107(55.1 \%)$ & $74(64.9 \%)$ & $0.029^{c}$ \\
\hline \multicolumn{5}{|l|}{${ }^{1}$ Effort-Reward ratio $>1$} \\
\hline \multicolumn{5}{|l|}{${ }^{2}$ Overcommitment score $>16$} \\
\hline \multicolumn{5}{|l|}{${ }^{*} t$ test } \\
\hline${ }^{\#}$ Chi-square-test & & & & \\
\hline
\end{tabular}


an effort-reward imbalance and overcommitment differed between the two occupational groups on ships (Table 2).

\section{Health-promoting conditions on board}

During the standardised interviews, $74.7 \%$ of the seafarer sample stated in free text that health management or tailormade health education was not established on their ships. $75.8 \%$ of the participants would appreciate receiving health information on board; particularly the ratings preferred tailor-made health campaigns implemented by the superiors on board $(83.7 \%)$.

Furthermore, the crews were asked about nutrition and sport on board:

\section{Healthy nutrition}

Concerning health-promoting conditions, 115 seafarers $(37.3 \%)$ were dissatisfied with the nutrition on board, regardless of the rank. Many seafarers complained about too little variety of foods, too much high-fat nutrition and too little fruit, salads and vegetables (Table 3 ).

\section{Sport activities}

A total of $42.5 \%$ of the seafarers stated that they did sports regularly. These participants of this study exercised more than $5 \mathrm{~h}$ per week ashore and only $3 \mathrm{~h}$ on board. The time spent doing sports on board was significantly lower for ratings than for officers (Table 3). $48.1 \%$ of the participants indicated a lack of motivation as the main reason to participate less in sport.

\section{Discussion}

According to the seafarers' statements in the present study, the officers had longer working days (10.4 vs. $9.3 \mathrm{~h}$; $p<0.001)$ and shorter daily sleep durations (7.0 vs. $7.6 \mathrm{~h}$; $p=0.016$ ) than ratings, which indicates a higher job-related stress load of this occupational group. In addition, the calculated effort score of the ERI questionnaire was distinctly lower than its median for the total study sample, suggesting that most seafarers regarded their job as not very stressful. The finding that officers had significantly higher effort scores corresponds to their obviously elevated job-related stress load. In this context, it must be considered that officers have a significantly shorter stay on board compared to ratings; this may explain why they also have relatively low effort scores (below the median score).

The reward score was also very high in the total group, so that satisfaction with their work environment can be assumed. Particularly officers seem to be satisfied due to their assessment of their job security $(p=0.001)$ and their job promotion. The significant differences in the job security can be explained by their permanent contracts, while the ratings usually only receive an employment contract for their current ship. Furthermore, compared to ratings, officers have better prospects for job promotion (up to captain or chief engineer of the current vessel).

The mean ER ratio across the study population was 0.53 , indicating a low risk of an effort-reward imbalance for seafarers as other studies conducted in land-based settings have shown distinctly higher risk rates. Among health workers the effort-reward ratio ranges quite widely from 0.47 up to 1.32 and the ER rate from 3.5 to $80.7 \%$ (Nguyen et al. 2018). In a study by Wu et al. (2019), $42 \%$ of professional drivers were assigned to the higher risk group of an

Table 3 Health-promoting conditions on board

\begin{tabular}{|c|c|c|c|c|c|}
\hline & \multirow[t]{2}{*}{ Study sample (308) } & \multicolumn{2}{|l|}{ Ranks } & \multicolumn{2}{|l|}{$\operatorname{Age}^{1}$} \\
\hline & & Ratings (194) & Officers (114) & $<37$ years $(157)$ & $\geq 37$ years $(151)$ \\
\hline \multicolumn{6}{|l|}{ Evaluation of nutrition on board } \\
\hline Too little variety & $90(29.2 \%)$ & $51(26.3 \%)$ & $39(34.2 \%)^{*}$ & $52(33.1 \%)$ & $38(25.2 \%)$ \\
\hline Too much high-fat nutrition & $66(21.4 \%)$ & $42(21.6 \%)$ & $24(21.1 \%)$ & $24(15.3 \%)$ & $42(27.8 \%)^{* *}$ \\
\hline Too little fruit & $62(20.1 \%)$ & $46(23.7 \%)$ & $16(14.0 \%)^{*}$ & $41(26.1 \%)$ & $21(13.9 \%)^{*}$ \\
\hline Too little salads and vegetables & $53(17.2 \%)$ & $32(16.5 \%)$ & $21(18.4 \%)$ & $28(17.8 \%)$ & $25(16.6 \%)$ \\
\hline Sport activities $^{2}(\%)$ & $131(42.5 \%)$ & $76(39.2 \%)$ & $55(48.2 \%)^{*}$ & $72(45.9 \%)$ & $59(39.1 \%)$ \\
\hline \multicolumn{6}{|l|}{ Frequency; hours per week (SD) } \\
\hline Ashore (while on vacation) & $5.1(4.1)$ & $5.1(4.0)$ & $5.1(4.3)$ & $5.3(4.0)$ & $5.1(4.1)$ \\
\hline On board & $3.1(2.9)$ & $2.3(3.1)$ & $3.7(2.6)^{* *}$ & $3.3(3.0)$ & $3.0(2.8)$ \\
\hline
\end{tabular}


effort-reward imbalance. In the present study, it is possible that the seafarers' answers about their efforts and demands at work indicate an adaptation to the specific work situation on board or a healthy worker effect. After adjustment for job-related parameters (average length of the working day and daily sleep duration), the risk of an effort-reward imbalance decreased, which is a sign that these job stressors influence this risk. However, the unexpectedly low ER ratio could also be an expression of dissimilation caused by fear of unemployment or social desirability (Eum et al. 2007).

Officers tended to be more often assigned to the group above the median of the ER ratio, which corresponds to the higher job-related stress load among officers mentioned above. Thus, they may have a somewhat elevated risk of an effort-reward imbalance correlating with cardiovascular risk factors. This different risk level between the two occupational groups, however, could be a result of a more pronounced dissimulation among ratings most often originating from South Asia. According to McKay (2007), Filipino seafarers see themselves as the new heroes ("Bagong Bayani") who take care of their families and have economic significance for their country with their financial transfers. The self-perception as "Bagong Bayani" might have an influence on the dissimulation.

Concerning overcommitment, this study revealed a high average score of 17.9 among seafarers. A study about teachers revealed a critical sum score of 16 (Lehr et al. 2010). Bus drivers-another occupation of the transport industry-showed a median overcommitment value of 13.2 (SD 4.4) (Tse et al. 2007). In total, this study proved the readiness of seafarers to exhaust their personal resources. There are several reasons for this important finding: the crews are involved in the tight shipboard routine for many months without being able to leave the ship to gain inner distance (Jensen et al. 2006). They are mainly focused on the tight working and living situation on board (Haka et al. 2011). Their time at sea is primarily determined by the need to support their family financially (McKay 2007). Furthermore, in the hierarchical structure of ship operation they often experience dominant and less understanding superiors (Sampson and Ellis 2019). In addition, seafarers are aware that safe ship operations require continuous, dedicated and responsible work (Tedesco et al. 2018; Lorenzi et al. 2018). All these circumstances might lead to elevated overcommitment among seafarers.

The risk of overcommitment was more than twice as high for officers as for ratings (OR 2.14; 95\% CI 1.78-2.37) regardless of the seafarers' age, the average length of their working day and their daily sleep duration. The working schedule of the officers demands a high overall work effort due to irregular shifts and especially long working hours (Oldenburg et al. 2009). The willingness to dedicate their time to job-related tasks to an extraordinarily high extent seems to be typical for this working group. The finding of differences regarding the risk of an effort-reward imbalance and overcommitment on board a ship highlights that the different ranks should be taken into account when evaluating workload and strain among the crew (Hansen et al. 2008).

Overcommitment is associated with a higher risk of cardiovascular diseases as a chronic effect. Health limitations, however, can also be caused by potentially harmful individual lifestyle habits (e.g., smoking, high consumption of alcohol, high-fat nutrition, lack of interest in physical activities during leisure time) (Sargent et al. 2017). Despite the physically demanding work on board, the BMI of the study sample averaged 26.4 and indicates slight overweight throughout the whole crew. Therefore, further research is needed focusing on the analysis of specific workload and strain in seafaring.

The high number of smokers in our study sample (48.7\%) proves that smoking is still more common for seafarers than for the general population. Tu and Jepsen (2016) already observed a high proportion of smokers/ex-smokers among Danish seafarers (43.1\%). Baygi et al. (2017) also described that smoking still counts as one of the most common cardiometabolic risk factors among seafarers. Although the reason for the high prevalence of smoking among shipboard crews is unclear (e.g., as a consequence of the shipboard stress or due to boredom), there is obviously a need for anti-smoking campaigns. Further studies are required to analyse the benefit of tailor-made health management for the maritime setting. Those studies should motivate the crew to change their lifestyle behaviour, for example through health information campaigns implemented by the superiors on board.

It became obvious during the interview on board that health management or tailor-made health education was not established on three quarters of the ships in our study. It is likely that the crews would perceive these measures as rewards by the shipping company, so that they consequently have a positive effect on the effort-reward balance. According to the present study, effective health promotion measures should encompass the provision of healthy food on board. Furthermore, the crews should be motivated to do more sport (e.g., by organising sport competitions or by providing appealing sport equipment on board). Physical activity is an effective preventive measure for staying in good health and avoiding overweight and musculoskeletal disorders (Baygi et al. 2017); hence it is particularly important for seafarers (Geving et al. 2007; Scovill et al. 2012).

A survey among 570 seafarers employed by a Norwegian shipping company unveiled that $70 \%$ did sports ashore at least twice a week, but only $39 \%$ did do so on board (Geving et al. 2007). In the present study, the self-reported time of $3 \mathrm{~h}$ of physical activity per week (in comparison to $5 \mathrm{~h}$ ashore) did not match the examiners' observations on board. It was obvious that the seafarers generally overestimated 
their weekly activity doing sport (probably taking all the physically challenging activities into account; regardless of whether they took place during leisure time or working hours). Nevertheless, the reported relation between sports activity ashore and on board can be taken as an indicator that the seafarers' subjective perception is that of reduced physical activity during their stay on the ships. This observation was especially prominent in ratings.

In total, seafarers are forced to not only spend their working hours but also their leisure time on board. Therefore, health awareness campaigning by superiors on board, a healthy and well-balanced food supply and well-equipped rooms for physical activity appear to be crucial to promoting the psychophysical health of the employees on board (Seppälä et al. 2017).

A strength of the present study is the high participation rate of the nearly $92 \%$. Such high rates are often observed in maritime field studies as most seafarers enjoy the opportunity to distract their thoughts from the often monotonous work and life routine on board. As a limitation of this study, it cannot be excluded that the applied method of face-to-face interviews could have promoted social desirability and that the special working environment of ships' crews studied may also have contributed to an answering bias. Consequently, the observed low risk of an effort-reward imbalance could in part be the result of seafarers' worry that disclosure of high work stress might threaten their job security. Furthermore, due to the cross-sectional design, it was not possible to assess long-time effects that may lead to an effort-reward imbalance or to health impairments.

\section{Conclusions}

Although an elevated risk of effort-reward imbalance was only observed among few seafarers, this study revealed a high prevalence of overcommitment particularly among officers. In the course of time, an overcommitment can lead to mental exhaustion. Therefore, the health-promoting conditions on board should be optimised in terms of situation and behaviour prevention (e.g., a balanced, healthy diet and motivation to exercise), which can also have a positive effect on the balance between effort and reward. Furthermore, longitudinal studies on the work-related demands and efforts of shipboard crews are recommended to determine possible chronic health effects.

Acknowledgements The authors would like to thank the seafarers and shipping companies for taking part in this study. Furthermore, many thanks are also owed to Dr. J. Hedtmann, Dr. C. Felten and Dr. B. Neubauer from the BG Verkehr for their support and the funding.

Author contributions $\mathrm{MO}$ and $\mathrm{HJJ}$ gave substantial contributions to the conception or design of the manuscript, or the acquisition, analysis or interpretation of data. They were equally involved in drafting the manuscript or revising it critically for important intellectual content. Both authors gave their final approval of the version published.

Funding Open Access funding enabled and organized by Projekt DEAL. This study was funded by the Berufsgenossenschaft für Transport und Verkehrswirtschaft ("BG Verkehr"), Hamburg.

Data availability The data sets used and/or analysed during the current study are available from the corresponding author on reasonable request.

Code availability Not applicable.

\section{Declarations}

Conflict of interest MO and HJJ declare that they have no conflict of interest/competing interests.

Ethical approval The study was approved by the Ethics Committee of the Hamburg Medical Association (no. PV4395), Germany. The study aims were introduced and explained to all seafarers prior to the interviews.

Consent to participate All participants gave written informed consent and were able to leave the interviews at any time.

Consent for publication Not applicable.

Open Access This article is licensed under a Creative Commons Attribution 4.0 International License, which permits use, sharing, adaptation, distribution and reproduction in any medium or format, as long as you give appropriate credit to the original author(s) and the source, provide a link to the Creative Commons licence, and indicate if changes were made. The images or other third party material in this article are included in the article's Creative Commons licence, unless indicated otherwise in a credit line to the material. If material is not included in the article's Creative Commons licence and your intended use is not permitted by statutory regulation or exceeds the permitted use, you will need to obtain permission directly from the copyright holder. To view a copy of this licence, visit http://creativecommons.org/licenses/by/4.0/.

\section{References}

Apostolatos C, Andria V, Licari J (2017) Overall comparative analysis of management and outcomes of cardiac cases reported on board merchant ships. Int Marit Health 68(4):190-195. https://doi.org/ 10.5603/IMH.2017.0036,indexedinPubmed:29297569

Baumler R, Bhatia BS, Kitada M (2020) Ship first: Seafarers' adjustment of records on work and rest hours. World Maritime University, Malmö

Baygi F, Jensen OC, Qorbani M, Farshad A, Salehi SA, Mohammadi $\mathrm{F}$ et al (2017) Pattern of some risk factors of cardiovascular diseases and liver enzymes among Iranian seafarers. Med J Islam Repub Iran 31:23. https://doi.org/10.18869/mjiri.31.23,index edinPubmed:29445652

Carotenuto A, Molino I, Fasanaro AM, Amenta F (2012) Psychological stress in seafarers: a review. Int Marit Health 63(4):188-194 (indexed in Pubmed: 24595974)

De Jonge J, Schaufeli DB (2002) Testing global and specific indicators of rewards in the Effort-Reward Imbalance Model: Does it make a 
difference? Eur J Work Organ Psy. https://doi.org/10.1080/13594 320244000265

Dragano N, Siegrist J, Nyberg ST, Lunau T, Fransson EI, Alfredsson L et al (2017) Effort-Reward Imbalance at work and incident coronary heart disease: a multicohort study of 90,164 individuals. Epidemiology 28(4):619-626. https://doi.org/10.1097/EDE. 0000000000000666

Edwards R, Holland J (2013) What is qualitative interviewing?: http:// eprints.ncrm.ac.uk/3276/1/complete_proofs.pdf. Accessed 20 September 2020.

Ehara M, Muramatsu S, Sano Y, Takeda S, Hisamune S (2006) The tendency of diseases among seamen during the last fifteen years in Japan. Ind Health 44(1):155-160. https://doi.org/10.2486/indhe lath.44155,indexedinPubmed:16610553

Eum KD, Li J, Lee HE, Kim SS, Paek P, Siegrist J et al (2007) Psychometric properties of the Korean version of the Effort-Reward Imbalance questionnaire: a study in a petrochemical company. Int Arch Occup Environ Health 80(8):653-661. https://doi.org/10. 1007/s00420-007-0174-3, indexedinPubmed:17541800

Geving IH, Jorgensen KU, Thi MS, Sandsund M (2007) Physical activity levels among offshore fleet seafarers. Int Marit Health 58(1-4):103-114 (indexed in Pubmed: 18350980)

Gilbert-Ouimet M, Trudel X, Brisson C, Milot A, Vézina M (2014) Adverse effects of psychosocial work factors on blood pressure: systematic review of studies on demand-control-support and effort-reward imbalance models. Scand J Work Environ Health 40(2):109-132. https://doi.org/10.5271/sjweh.3390

Haka M, Borch DF, Jensen C, Leppin A (2011) Should I stay or should I go? Motivational profiles of Danish seafaring officers and nonofficers. Int Marit Health 62(1):20-30 (indexed in Pubmed: 21534222)

Hansen HL, Tuchsen F, Hannerz H (2005) Hospitalisations among seafarers on merchant ships. Occup Environ Med 62(3):145-150. https://doi.org/10.1136/oem.2004.014779 (indexedinPubmed:15723878)

Hansen HL, Laursen LH, Frydberg M, Kristensen S (2008) Major differences in rates of occupational accidents between different nationalities of seafarers. Int Marit Health 59(1-4):7-18 (indexed in Pubmed: 19227734)

Hjarnoe L, Leppin A (2014) What does it take to get a healthy diet at sea? A maritime study of the challenges of promoting a healthy llifestyle at the workplace at sea. Int Marit Health 65(2):79-86. https://doi.org/10.5603/IMH.2014.0018,indexedinPubmed:25231 331

Jamshed S (2014) Qualitative research method-interviewing and observation. J Basic Clin Pharm 5(4):87-88. https://doi.org/10.4103/ 0976-0105.141942.indexedinPubmed:25316987

Jaremin B, Kotulak E (2003) Myocardial infarction (MI) at the worksite among Polish seafarers. The risk and the impact of occupational factors. Int Marit Health 54(1-4):26-39 (indexed in Pubmed: 14974775)

Jensen OC, Sørensen JF, Thomas M, Canals ML, Nikolic N, Hu Y (2006) Working conditions in international seafaring. Occup Med (lond) 56(6):393-397. https://doi.org/10.1093/occmed/kq1038 (indexedinPubmed:16804089)

Jepsen JR, Zhao Z, van Leeuwen WM (2015) Seafarer fatigue: a review of risk factors, consequences for seafarers' health and safety and options for mitigation. Int Marit Health 66(2):106-117. https:// doi.org/10.5603/IMH.2015.0024,indexedinPubmed:26119681

Junior FM, Pereira C, Santos MM (2017) The health and welfare of working judges in Brazil. A quantitative and qualitative analysis. Occup Safety Hygiene 99-104.

Kivimäki M, Steptoe A (2018) Effects of stress on the development and progression of cardiovascular disease. Nat Rev Cardiol 15(4):215229. https://doi.org/10.1038/nrcardio.2017.189
Lehr D, Koch S, Hillert A (2010) Where is the (im)balance? Necessity and construction of evaluated cut-off points for EffortReward Imbalance and overcommitment. J Occup Organ Psychol 83(1):251-261. https://doi.org/10.1348/096317909X406772

Li J, Herr RM, Allen J, Stephens C, Alpass F (2017) Validating the short measure of the Effort-Reward Imbalance Questionnaire in older workers in the context of New Zealand. J Occup Health 59(6):495-505. https://doi.org/10.1539/joh.17-0044-OA,index edinPubmed:28835574

Lochner M, Duenser A (2018) Analysis of maritime team workload and communication dynamics in standard and emergency scenarios. J Ship Trade 3(1):2

Lorenzi G, Mariani MG, Panari C (2018) Safety in shipping: the role of the human factor. G Ital Med Lav Ergon 40(2):67-75 (indexed in Pubmed: 30480390)

McKay SC (2007) Filipino sea men: constructing masculinities in an ethnic labour niche. J Etnic Migration Stud 33(4):617-633. https://doi.org/10.1080/13691830701265461

Van Nguyen H, Le Dinh M, Van Nguyen T, Nguyen Ngoc D, Tran Thi Ngoc A, Nguyen D (2018) A systematic review of EffortReward Imbalance among health workers. Int J Health Plan Manage. https://doi.org/10.1002/hpm.2541 (indexed in Pubmed: 29722057; online ahead of print)

Oldenburg M, Jensen HJ, Latza U, Baur X (2008) Coronary risks among seafarers aboard German-flagged ships. Int Arch Occup Environ Health 81(6):735-741. https://doi.org/10.1007/s00420007-0261-5, indexedinPubmed: 17909838

Oldenburg M, Jensen HJ, Latza U, Baur X (2009) Seafaring stressors aboard merchant and passenger ships. Int J Public Health 54(2):96-105. https://doi.org/10.1007/s00038-009-7067-z,index edinPubmed: 19288290

Oldenburg M, Jensen HJ, Wegner R (2013a) Burnout syndrome in seafarers in the merchant marine service. Int Arch Occup Environ Health 86(4):407-416. https://doi.org/10.1007/s00420-012-07717,indexedinPubmed:22526089

Oldenburg M, Harth V, Jensen HJ (2013b) Overview and prospect: food and utrition of seafarers on merchant ships. Int Marit Health 64(4):191-194. https://doi.org/10.5603/imh.2013.0003,index edinPubmed:24408139

Sampson H, Ellis N (2019) Seafarers' mental health and wellbeing. Seafarers International Research Centre

Sargent C, Gebruers C, O’Mahony J (2017) A review of the physiological and psychological health and wellbeing of naval service personnel and the modalities used for monitoring. Mil Med Res 4:1. https://doi.org/10.1186/s40779-016-0112-3 (indexedinPubmed:28116111)

Scovill SM, Roberts TK, McCarty DJ (2012) Health characteristics of Inland waterway merchant marine captains and pilots. Occup Med (lond) 62(8):638-641. https://doi.org/10.1093/occmed/kqs156 (indexedinPubmed:22987812)

Seppälä T, Hankonen N, Korkiakangas E, Ruusuvuori J, Laitinen J (2017) National policies for the promotion of physical activity and healthy nutrition in the workplace context: a behaviour change wheel guided content analysis of policy papers in Finland. BMC Public Health 18(1):87. https://doi.org/10.1186/s12889-017-45743 (indexedinPubmed:28764754)

Siegrist J (2002) Effort-Reward Imbalance at work and health. In: Perrewe P, Ganster D (eds) Research in occupational stress and well beeing, Volumen 2: Historical and current perspectives on stress and health. JAI Elsevier, New York, pp 261-291

Siegrist K, Rodel A, Siegrist J (2003) A theory-based study on psychosocial workload as an instrument of health promotion in a hospital. Gesundheitswesen 65(11):612-619. https://doi.org/10. 1055/s-2003-44625 (indexedinPubmed:14639518)

Siegrist J, Starke D, Chandola T, Godin I, Marmot NI et al (2004) The measurement of Effort-Reward Imbalance at work: European 
comparisons. Soc Sci Med 58(8):1483-1499. https://doi.org/10. 1016/S0277-9536(03)00351-4,indexedinPubmed:14759692

Siegrist J, Wege N, Pühlhofer F, Wahrendorf M (2008) A short generic measure of work stress in the era of globalization: effort-reward imbalance. Int Arch Occup Environ Health. https://doi.org/10. 1007/s00420-008-0384-3

Siegrist J, Wege N, Pühlhofer F, Wahrendorf M (2009) A short generic measure of work stress in the era of globalization Effort-Reward Imbalance. Int Arch Occup Environ Health 82(8):1005-1013. https://doi.org/10.1007/s00420-008-0384-3,indexedinPubmed: 19018554

Siegrist J, Wahrendorf M, Goldberg M, Zins M, Hoven H (2018) Is effort-reward imbalance at work associated with different domains of health functioning? Baseline results from the French CONSTANCES study. Int Arch Occup Environ Health 92(4):467-480

Siegrist J, Montano D (2014) Psychometric properties of the EffortReward Imbalance Questionnaire. https://www.uniklinik-duess eldorf.de/fileadmin/Fuer-Patienten-und-Besucher/Kliniken-Zentr en-Institute/Institute/Institut_fuer_Medizinische_Soziologie/Datei en/ERI/ERI_Psychometric-New.pdf. Last accessed on 07.03.2021.

Siegrist J, Klein D, Voigt KH (1997) Linking sociological with physiological data: the model of Effort-Reward Imbalance at work. Acta Physiol Scand Suppl 640:112-116 (indexed in Pubmd: 9401620)

Tedesco LMR, Ferrara P, Stromillo L, Arnese A, Albano L (2018) Seafarers' perceptions of job demand: a cross-sectional study. Arch Environ Occup Health 73(5):278-283. https://doi.org/10.1080/ 19338244.2017.1342590,indexedinPubmed:28622113

Tse JML, Fin R, Mearns K (2007) Facets of job effort in bus driver health: deconstructing "Effort" in the Effort-Reward Imbalance model. J Occup Health Psychol 12(1):48-62. https://doi.org/10. 1037/1076-8998.12.1.48,indexedinPubmed:17257066

Tu M, Jepsen JR (2016) Hypertension among Danish seafarers. Int Marit Health 67(4):196-204. https://doi.org/10.5603/IMH.2016. 0037 (indexedinPubmed:28009392)

Wahrendorf M, Dragano N, Siegrist J (2014) Social position, work stress, and retirement intentions: a study with older employees from 11 European countries. Eur Sociol Rev 29(4):792-802. https://doi.org/10.1093/esr/jcs058

Wei-Te Wu, Tsai S-S, Wang C-C, Lin Y-J, Trong-Neng Wu, Shih T-S, Liou S-H (2019) Professional driver's job stress and 8-year risk of cardiovascular disease: the Taiwan bus driver cohort study. Epidemiology 1:39-47. https://doi.org/10.1097/EDE.0000000000 001003 (indexedinPubmed:31181005)

Westenhoefer J, von Katzler R, Jensen HJ, Zyriax BC, Harth V, Oldenburg M (2018) Cultural differences in food and shape related attitudes and eating behavior are associated with differences of body bass index in the same food environment: cross- sectional results from the seafarer nutrition study of Kiribati and European seafarers on merchant ships. BMC Obes 5:1. https://doi.org/10. 1186/s40608-018-0180-x (indexedinPubmed:29416869)

WHO. What is raised blood pressure (hypertension)? 2015: https:// www.who.int/features/qa/82/en/. Accessed 20 September 2020.

Wu WT, Tsai SS, Wang CC, Lin YJ, Wu TN, Shih TS, Liou S-H (2019) Professional driver's job stress and 8-year risk of cardiovascular disease. The Taiwan bus driver cohort study. Epidemiology 30:39-47. https://doi.org/10.1097/EDE.0000000000001003 (indexedinPubmed:31181005)

Zyriax BC, von Katzler R, Westenhoefer J, Jensen HJ, Harth V, Oldenburg M (2018) Food Offerings on board and dietary intake of European and Kiribati seafarers-cross-sectional data from the seafarer nutrition study. J Occup Med Toxicol 13:9. https:// doi.org/10.1186/s12995-018-0190-0 (indexed in Pubmed: 29988947)

Publisher's Note Springer Nature remains neutral with regard to jurisdictional claims in published maps and institutional affiliations. 